\title{
Caregiver Burden of Primary Caregivers for People with Spinal Cord Injury (SCI) Residing at Calicut District Kerala
}

\author{
Abidfaheem Thelakkadan ${ }^{1}$, Leena Kunnath Chacko² \\ ${ }^{1}$ Department of Community Health Nursing, Santhi College of Nursing, Calicut, Kerala, \\ India. ${ }^{2}$ Department of Community Health Nursing, Yenepoya Nursing College, Yenepoya \\ (Deemed to Be University), Mangalore, Karnataka, India.
}

\section{ABSTRACT}

\section{BACKGROUND}

The study aims to assess the caregiver burden of primary caregivers of people with spinal cord injury by using Caregiver Burden Scale (CBS), find the association between caregiver burden and selected socio-demographic variables and find the association between caregiver burden and characteristics of individuals with spinal cord injury.

\section{METHODS}

A cross sectional study was conducted from June 2019 to December 2019 among primary caregivers of patients with spinal cord injury (SCI) residing in selected communities of Calicut district, Kerala state, India. Purposive sampling technique was used to select samples. Caregiver burden was assessed by Zarit Caregiver Burden Interview. Characteristics of caregivers and individuals with spinal cord injury were collected by structured interview.

\section{RESULTS}

Study was conducted among 100 primary caregivers of individuals with spinal cord injury. The mean score of caregiver burden is 45.3 with SD 11.4. Out of the total sample, $40 \%$ of the caregivers suffered from mild to moderate burden, another $40 \%$ suffered from moderate to severe burden and the remaining $20 \%$ of them suffered from severe caregiver burden. The study also found an association between caregiver burden score with characteristics of caregivers such as age $(p=0.038)$, gender $(p=$ $0.02)$ and marital status $(p=0.048)$. Study also found an association between the gender of patient $(p=0.001)$ and level of injury $(p=0.001)$.

\section{CONCLUSIONS}

Majority of the sample showed moderate to severe level of caregiver burden. The study helped to find out multiple factors affecting caregiver burden. Health care system can identify these factors and consider them while planning and implementing different programs for individuals with SCI. Measures can be considered to alleviate caregiver burden by considering the findings of the current study and the community can plan different rehabilitative services which can reduce the burden of caregivers.

\section{KEY WORDS}

Caregiver Burden, Spinal Cord Injury, Primary Caregivers
Corresponding Author: Dr. Abidfaheem Thelakkadan, Associate Professor, Santhi College of Nursing, Omassery - 673582, Calicut, Kerala, India.

E-mail:abidfaheemtri@gmail.com

DOI: $10.14260 / \mathrm{jemds} / 2021 / 101$

How to Cite This Article:

Thelakkadan A, Chacko LK. Caregiver burden of primary caregivers for people with spinal cord injury (SCI) residing at Calicut District Kerala. J Evolution Med Dent Sci 2021;10(08):458-462, DOI: 10.14260/jemds/2021/101

Submission 25-08-2020,

Peer Review 17-12-2020

Acceptance 23-12-2020,

Published 22-02-2021.

Copyright (C) 2021 Abidfaheem Thelak Kadan et al. This is an open access article distributed under Creative Commons Attribution License [Attribution 4.0 International (CC BY 4.0)] 


\section{BACKGROUND}

Spinal cord injury is truly a devastating injury with profound consequences to the individual, his family and society. WHO (World Health Organization) recognises it as a major musculoskeletal condition that presents as a serious disease burden. Spinal cord injury is a traumatic harm to the spinal cord that can result in alteration of normal motor, sensory and anatomic function. ${ }^{1}$ every year, about 40 million people worldwide suffer from SCI. Every year 40 - 80 new cases per million SCI are reporting world-wide. ${ }^{2}$

Spinal cord injury does not exclusively compromise the life of the individual after the incident. Considering the decrease in functional independence and the social and psychological impact on the individual's life after injury, ${ }^{3}$ his immediate family suffers consequences that require restructuring to meet the needs arising from the health conditions.

While the entire family is affected by the occurrence, it is one of its members, known as the family caregiver, who assume responsibility for the care of the individual and his needs. In this way, the caregiver divides her / his time and attention between the new demands with the family member who suffered the SCI and her / his own activities and professional, family, social and marital roles, and may consequently become overwhelmed. ${ }^{4}$

Primary caregivers refers to the caregivers living together with the patients and often have to take over many of the responsibilities of the patient. He / she can or can't be a family member. The term family caregiver is used more than informal caregiver, since the family caregiver is a family member or relative who takes care of a family member, with complicity and commitment in this regard. ${ }^{5}$ Throughout the process, the impact of the activities exercised by the family caregiver can create problems of a bio psychosocial and spiritual nature that influence her life and the quality of care provided.6-7

After the SCI, depending on the neurological level, the individual becomes dependent on the caregiver to perform various Activities of Daily Living (ADL), especially in the first year after injury. Studies show that, in carrying out their role, primary caregivers go through various situations that can result in caregiver burden.6-7

Caregiver burden is defined as a perception that the individual has in relation to his / her physical health, social life, emotional status as a result of caring for a diseased individual resulting in the concept of burden as the product of a specific, subjective and interpretive process of chronic disease. It can be seen as a multidimensional concept that encompasses the bio psychosocial sphere and results in the search for a balance between the variables: time available for care, financial resources, and psychological, physical and social conditions, responsibilities, and, distribution of roles. ${ }^{7}$

One of the instruments used by researchers in order to measure caregiver burden is the Caregiver Burden Scale (CB Scale). This scale was used to assess the burden of caregivers of patients with nervous system disease. ${ }^{7}$ It composed of 22 questions divided into five domains: general strain, isolation, disappointment, emotional involvement and environment. For each question, responses could be attributed from 1 to 4 , with $1=$ in no way; 2 = rarely $3=$ sometimes, and $4=$ frequently. The higher the value, the greater the impact / caregiver burden. A global score can be obtained for caregiver burden, or an individual score for each domain. The overall score is obtained by calculating the arithmetic mean of the 22 items, and the score for each domain is obtained through the arithmetic average of the values of each item comprising that domain.

The new caregiver activities demand changes in their lifestyle, which can compromise their health, social linkages and economic status. For the exercise of such activities, the caregiver needs to be prepared from the first hospitalisation of individuals with SCI to give continuity of care in the home and minimize the effects of caregiver burden.

Thus the current study tried to find out the caregiver burden of caregivers of individuals with SCI and different factors determining the caregiver burden.

\section{METHODS}

A cross sectional study was conducted from June 2019 to December 2019 among primary caregivers of patients with spinal cord injury residing in Calicut district, Kerala. Purposive sampling technique was used to select the samples.

\section{Inclusion Criteria}

Primary caregivers proving care to people with spinal cord injury, adult caregivers above 18 years, caregivers providing care for a period of above 6 months, people who are able to read and write in Malayalam and caregivers who are willing to participate in the study. Caregivers suffering from any major disabling condition which indirectly add on to the burden of care giving were excluded from the study.

Before collecting data written informed consent was obtained from each participant. Data was collected from homes of the participants. Total 100 primary caregivers who met the sampling criteria were included in the study. Demographic and clinical data were collected using a structured interview schedule. Caregiver burden was assessed by Zarit caregiver Burden Interview (ZBI) in Malayalam for Indian language ${ }^{7}$. The scale assesses subjective burdens including the role and personal burden, in 22 items. Each item is scored on a 5-point scale from 0 to 4 : never (0), rarely (1), sometimes (2), quite frequently (3) and almost always (4), with the total score of 88 . A higher score indicates greater burden for the caregivers of patients with SCI. Based on the participants' scores of ZBI, they were categorised into four groups representing different severity levels of burden. Scores in the range of $0-20$ were classified as 'little or no burden', scores 21 - 40 represented 'mild-to-moderate burden', range 41 - 60 was categorised as 'moderate-to-severe burden' and finally scores between 61 and 88 were classified as 'severe burden'. This study was approved by MIMS Hospital Ethics Committee, Calicut, Kerala state, India.

\section{Statistical Analysis}

Statistical analysis was performed by SPSS 21.0 version. Analysis was done using descriptive statistics (frequency, percentage, mean and SD) and inferential statistics (independent sample t-test). All the hypotheses were tested at 0.05 level of significance. 


\section{RESULTS}

\section{Care Giver's Demographic Characteristics}

The mean age of the participants was $41.7 \pm 12.66$. All the primary caregivers are living with the individuals with SCI. Other demographic characteristics are given in Table 1. Table 1 shows that $57 \%$ of the study participants were aged above 35 years and $70 \%$ of them were females. Out of total samples, $55 \%$ had primary education and $45 \%$ of them were daily wagers. $40 \%$ of the care givers were parents and $35 \%$ were spouses. Majority (75\%) of the primary care givers were married and $55 \%$ were being the only care givers.

\begin{tabular}{|c|c|c|c|}
\hline \multicolumn{2}{|c|}{ Sl. No. Demographic Variables } & \multirow[t]{2}{*}{ Frequency (f) } & \multirow[t]{2}{*}{ Percentage (\%) } \\
\hline \multirow{3}{*}{1} & Age in years & & \\
\hline & Less than 35 & 43 & 43 \\
\hline & More than 35 & 57 & 57 \\
\hline \multirow{3}{*}{2} & Gender & & \\
\hline & Male & 30 & 30 \\
\hline & Female & 70 & 70 \\
\hline \multirow{5}{*}{3} & Education & & \\
\hline & No formal education & 10 & 10 \\
\hline & Primary & 55 & 55 \\
\hline & Secondary & 20 & 20 \\
\hline & Degree and above & 15 & 15 \\
\hline \multirow{4}{*}{4} & Occupation & & \\
\hline & Home maker & 30 & 30 \\
\hline & Daily wager & 45 & 45 \\
\hline & Professional & 25 & 25 \\
\hline \multirow{5}{*}{5} & Relationship with patient & & \\
\hline & Spouse & 35 & 35 \\
\hline & Parents & 40 & 40 \\
\hline & Siblings & 10 & 10 \\
\hline & Children & 15 & 15 \\
\hline \multirow{3}{*}{6} & Marital status & & \\
\hline & Married & 75 & 75 \\
\hline & Unmarried & 25 & 25 \\
\hline \multirow{3}{*}{7} & Being only caregiver & & \\
\hline & Yes & 55 & 55 \\
\hline & No & 45 & 45 \\
\hline \multicolumn{4}{|c|}{ Table 1. Caregiver's Demographic Characteristics } \\
\hline$=100$ & & & \\
\hline
\end{tabular}

\begin{tabular}{|c|c|c|c|}
\hline Sl. No. & Demographic Variables & Frequency (f) & Percentage (\%) \\
\hline 1 & $\begin{array}{l}\text { Age in Years } \\
\text { Less than } 35 \\
\text { More than } 35\end{array}$ & $\begin{array}{l}56 \\
44\end{array}$ & $\begin{array}{l}56 \\
44\end{array}$ \\
\hline 2 & $\begin{array}{l}\text { Gender } \\
\text { Male } \\
\text { Female }\end{array}$ & $\begin{array}{l}65 \\
35\end{array}$ & $\begin{array}{l}65 \\
35\end{array}$ \\
\hline 3 & $\begin{array}{c}\text { Cause of Injury } \\
\text { Road Traffic Accident } \\
\text { Fall }\end{array}$ & $\begin{array}{l}40 \\
60\end{array}$ & $\begin{array}{l}40 \\
60\end{array}$ \\
\hline 4 & $\begin{array}{c}\text { Level of Injury } \\
\text { Paraplegia } \\
\text { Tetraplegia }\end{array}$ & $\begin{array}{l}80 \\
20\end{array}$ & $\begin{array}{l}80 \\
20\end{array}$ \\
\hline 5 & $\begin{array}{c}\text { Duration of injury } \\
\text { Less than } 1 \text { year } \\
1 \text { - } 5 \text { Years } \\
\text { More than } 5 \text { years }\end{array}$ & $\begin{array}{l}20 \\
45 \\
35\end{array}$ & $\begin{array}{l}20 \\
45 \\
35\end{array}$ \\
\hline \multicolumn{4}{|c|}{ Table 2. Characteristics of Individuals' with SCI } \\
\hline
\end{tabular}

\begin{tabular}{|c|c|c|c|c|}
\hline $\begin{array}{l}\text { Sl. } \\
\text { No. }\end{array}$ & $\begin{array}{l}\text { Demographic } \\
\text { Variables }\end{array}$ & $\mathbf{N}$ & $\begin{array}{l}\text { Caregiver Burden Score } \\
\text { (Mean } \pm \text { SD) }\end{array}$ & P Value \\
\hline 1 & $\begin{array}{c}\text { Age } \\
\text { Less than } 35 \\
35 \text { or more }\end{array}$ & $\begin{array}{l}43 \\
57\end{array}$ & $\begin{array}{c}42.58 \pm 9.45 \\
47.35 \pm 12.39\end{array}$ & $0.038^{*}$ \\
\hline 2 & $\begin{array}{l}\text { Gender } \\
\text { Male } \\
\text { Female }\end{array}$ & $\begin{array}{l}43 \\
57\end{array}$ & $\begin{array}{c}50.67 \pm 11.67 \\
43.0 \pm 10.58\end{array}$ & $0.02^{*}$ \\
\hline 3 & $\begin{array}{c}\text { Marital status } \\
\text { Married } \\
\text { Unmarried }\end{array}$ & $\begin{array}{l}75 \\
25\end{array}$ & $\begin{array}{c}44.0 \pm 12.33 \\
49.2 \pm 6.90\end{array}$ & $0.048^{*}$ \\
\hline 4 & $\begin{array}{c}\text { Being only caregiver } \\
\text { Yes } \\
\text { No } \\
\end{array}$ & $\begin{array}{l}55 \\
45 \\
\end{array}$ & $\begin{array}{c}44.0 \pm 12.58 \\
49.2 \pm 9.33 \\
\end{array}$ & 0.82 \\
\hline & $\begin{array}{r}\text { Table 3. Associa } \\
\text { Demograph }\end{array}$ & & $\begin{array}{l}\text { een Caregiver Burden anc } \\
\text { cteristics of Caregivers }\end{array}$ & \\
\hline
\end{tabular}

\section{Characteristics of Spinal Cord Injury} Individuals

Table 2 shows $56 \%$ of the individuals with SCI had age less than 35 years, and $65 \%$ of them were females. In $60 \%$ of individuals with SCI, the cause of injury was fall from height and the reaming $40 \%$ due to road traffic accidents. Among the individuals with SCI, $80 \%$ of them were paraplegic and the remaining $20 \%$ tetraplegic. The duration of injury was more than 5 years in $35 \%$ of the individuals with SCI.

\section{Caregiver Burden}

The mean score of caregiver burden is 45.3 with SD 11.4. Out of total sample, $40 \%$ of the caregivers suffered from mild to moderate burden, another $40 \%$ suffered from moderate to severe burden and remaining $20 \%$ of them suffered from severe caregiver burden.

Association between Caregiver Burden and Demographic Characteristics of Caregivers Independent sample t test was used to find out the association between caregiver burden and selected demographic characteristics of caregivers.

Table 3 shows there is a significant association between age of care giver and care giver burden ( $p=0.038)$, that is people of age more than 35 years had more caregiver burden than individuals with less than 35 years. There is also a significant association between gender and care giver burden $(\mathrm{p}=0.02)$, that is male caregivers showed more caregiver burden than females. Married caregivers showed less caregiver burden than unmarried groups and it is significant at 0.05 level $(p=0.048)$. But there was no significant difference seen among being only caregiver and multiple caregivers.

\begin{tabular}{|c|c|c|c|c|}
\hline $\begin{array}{l}\text { Sl. } \\
\text { No. }\end{array}$ & $\begin{array}{l}\text { Demographic } \\
\text { Variables }\end{array}$ & $\mathbf{N}$ & $\begin{array}{l}\text { Caregiver Burden Score } \\
\quad \text { (Mean } \pm \text { SD) }\end{array}$ & P Value \\
\hline \multirow{3}{*}{1} & Age & & & \multirow{3}{*}{0.078} \\
\hline & Less than 35 & 56 & $47.09 \pm 9.71$ & \\
\hline & 35 or more & 44 & $43.02 \pm 13.03$ & \\
\hline \multirow{3}{*}{2} & Gender of Patients & & & \multirow{3}{*}{$0.001^{*}$} \\
\hline & Male & 65 & $42.31 \pm 11.24$ & \\
\hline & Female & 35 & $50.86 \pm 9.63$ & \\
\hline \multirow{3}{*}{3} & Cause of Injury & & & \multirow{3}{*}{0.080} \\
\hline & Road Traffic Accident & 40 & $47.75 \pm 11.56$ & \\
\hline & Fall & 60 & $43.67 \pm 11.11$ & \\
\hline \multirow{3}{*}{4} & Duration of Injury & & & \multirow{3}{*}{0.993} \\
\hline & Less than 5 Years & 65 & $45.31 \pm 10.08$ & \\
\hline & 5 Years or more & 35 & $45.29 \pm 13.71$ & \\
\hline \multirow{3}{*}{5} & Level of Injury & & & \multirow{3}{*}{$0.001^{*}$} \\
\hline & Paraplegia & 80 & $40.63 \pm 7.19$ & \\
\hline & Tetraplegia & 20 & $64.0 \pm 2.05$ & \\
\hline \multicolumn{5}{|c|}{$\begin{array}{c}\text { Table 4. Association between Caregiver Burden Score and } \\
\text { Characteristics of Individual with SCI }\end{array}$} \\
\hline
\end{tabular}

\section{Association between Caregiver Burden Score} and Characteristics of Individual with SCI

Independent sample $t$ test was used to find out the association between caregiver burden and characteristics of individual with SCI. Table 4 shows caregiver burden is more among caregivers of individuals with less than 35 years but the difference is not significant $(\mathrm{p}=0.078)$. Caregivers of Male individuals with SCI showed less caregiver burden than females and it is significant $(p=0.001)$. There was no significant difference established with cause of injury and 
caregiver burden $(p=0.080)$. Caregivers of Paraplegic patients showed significant reduction in caregiver burden than tetraplegic patients $(\mathrm{p}=0.001)$. There was no significant difference established with duration of injury $(p=0.993)$ and caregiver burden.

\section{DISCUSSION}

The study tried to find out the caregiver burden among primary caregivers of individuals with SCI. Demographic data of primary care givers showed that $57 \%$ of them were aged above 35 years and $70 \%$ of them were females. Out of total samples, $55 \%$ had primary education and $45 \%$ of them were daily wagers. $40 \%$ of the care givers were parents and $35 \%$ were spouses. Majority ( $75 \%$ ) of the primary care givers were married and $55 \%$ were being the only care givers. The demographic data of individuals with SCI showed that $56 \%$ of the individuals with SCI had age less than 35 years, and $65 \%$ of them were females. In $60 \%$ of individuals with SCI, the cause of injury was fall from height and the reaming $40 \%$ due to road traffic accidents. Among the individuals with SCI, $80 \%$ of them were paraplegic and the remaining $20 \%$ tetraplegic. The duration of injury was more than 5 years in $35 \%$ of the individuals with SCI.

The caregiver burden was assessed by Zarit caregiver Burden Interview. The study also tried to find out different factors associated with caregiver burden. The mean score of caregiver burden is 45.3 with SD 11.4 and $40 \%$ of the caregivers suffered from mild to moderate burden, another 40 $\%$ suffered from moderate to severe burden and $20 \%$ of them suffered from severe caregiver burden.

People in age group of more than 35 years were having more caregiver burden than individuals with less than 35 years and it is significant $(p=0.038)$. Male caregivers showed more caregiver burden than females and it is significant $(\mathrm{p}=$ 0.02). Married caregivers showed less caregiver burden than unmarried groups and it is significant at 0.05 level $(p=0.048)$. But there was no significant difference seen among being only caregiver and multiple caregivers.

Caregiver burden is more among caregivers taking care of SCI individuals with less than 35 years but the difference is not significant $(p=0.078)$. Caregivers of Male individuals with SCI showed less caregiver burden than females and it is significant ( $p=0.001)$. There was no significant difference established with cause of injury and caregiver burden. Caregivers of Paraplegic patients showed significant reduction in caregiver burden than tetraplegic patients $(p=0.001)$. There was no significant difference established with duration of injury and caregiver burden.

\section{Comparison with Literature Data}

The current study revealed that $40 \%$ of the caregivers suffered from mild to moderate burden, another $40 \%$ suffered from moderate to severe burden. A similar study conducted by Naveen RS $^{8}$ revealed that $40 \%$ of the participants had mild to moderate caregiver stress and $38 \%$ had moderate to severe stress and the result is supporting the current study.
The current study revealed that the mean caregiver burden of caregivers of individuals with SCI was 45.3 with SD 11.4 which was supported by another study conducted by Z Khazaeipour et $\mathrm{al}^{9}$ to find out the caregiver burden among individuals with SCI by using caregiver burden interview and found the mean caregiver burden was $38.86 \pm 15.25$.

The current study revealed there was significant association between caregiver burden with gender and marital status of caregivers. A study conducted by $\mathrm{Z}$ Khazaeipour et $\mathrm{al}^{9}$ revealed there was no significant association between caregiver burden with gender and marital status which is contradictory to the current study.

The current study revealed caregivers of tetraplegic individuals had more caregiver burden than paraplegic individuals, which was supported by the study conducted by Khazaeipour et $\mathrm{al}^{9}$ and found caregivers of tetraplegic individuals suffered more caregiver burden.

Another study conducted by Eline W M Scholten et al on caregiver burden and well-being in partners of persons with spinal cord injury 5 years after discharge from first inpatient rehabilitation showed that about $43 \%$ of the partners experienced high levels of caregiver burden which is supporting the current study finding. ${ }^{10}$

Another study conducted by Paula Cristina Nogueira et al showed that there is significant relationship between ages of the care giver with care giver burden which is supporting the findings of the current study. The study also found male care givers had more care giver burden which also supporting the results of present study. ${ }^{11}$

\section{CONCLUSIONS}

The current study tried to find out the caregiver burden among caregivers of individuals with SCI. Majority of the sample showed moderate to severe levels of caregiver burden. The study also helped to determine the various factors affecting caregiver burden. Health care system can identify these factors and consider them while planning and implementing different programs for individuals with SCI. Measures can be considered to alleviate caregiver burden by considering the findings of the current study and the community can plan different rehabilitative services which can reduce the burden of caregivers.

\section{Limitations}

Caregiver burden is assessed only in primary caregivers. Patient variables such as co-morbidities, complications, social support were not considered. Since data was collected from home settings, patients admitted in the hospital during the data collection period were not included.

Data sharing statement provided by the authors is available with the full text of this article at jemds.com.

Financial or other competing interests: None.

Disclosure forms provided by the authors are available with the full text of this article at jemds.com. 


\section{REFERENCES}

[1] Gosselin RA, Coppotelli C. A follow up study of patients with spinal cord injury in Sierra Leone. Int Orthop 2005;29(5):330-2.

[2] WHO. International perspectives on spinal cord injury. 2013.

[3] Rabeh SAN, Caliri MHL. Capacidade funcional em indivíduos com lesão de medula espinal. Acta Paul Enferm 2010;23(3):321-7.

[4] Faro ACM. Atividades realizadas no domicílio pelo cuidador familiar da pessoa com lesão medular. Rev Paul Enferm 2001;20(2):33-43.

[5] Medeiros MMC, Ferraz MB, Quaresma M, et al. Adaptação ao contexto cultural brasileiro e validação do caregiver burden scale. Rev Bras Reumatol 1998;38(4):193-9.

[6] Robison J, Fortinsky R, Kleppinger A, et al. A broader view of family caregiving: effects of caregiving and caregiver conditions on depressive symptoms, health, work and social isolation. J Gerontol B Psychol Sci Soc Sci 2009;64(6):788-98.
[7] Zarit SH, Reever KE, Bach-Peterson J. Relatives of the impaired elderly: correlates of feelings of burden. Gerontologist 1980;20(6):649-55.

[8] Naveen RS. Burden in the caregivers of traumatic spinal cord injuries. J Evolution Med Dent Sci 2016;5(100):7310-13.

[9] Khazaeipour Z, Rezaei-Motlagh F, Ahmadipour E, et al. Burden of care in primary caregivers of individuals with spinal cord injury in Iran: its association with sociodemographic factors. Spinal Cord 2017;55(6):595600.

[10] Scholten EWM, Kieftenbelt A, Hillebregt CF, et al. Provided support, caregiver burden and well - being in partners of persons with spinal cord injury 5 years after discharge from first inpatient rehabilitation. Spinal Cord 2018;56(5):436-46.

[11] Nogueira PC, Rabeh SAN, Caliri MHL, et al. Burden of care and its impact on health-related quality of life of caregivers of individuals with spinal cord injury. Rev Lat Am Enfermagem 2012;20(6):1048-56. 